\title{
Horizontal transfer of OXA-23-carbapenemase-producing Acinetobacter species in intensive care units at an academic complex hospital, Durban, KwaZulu-Natal, South Africa
}

\author{
Khine Swe Swe-Han ${ }^{a b *}$, Melendhran Pillay ${ }^{a}$, Desmond Schnugh', Koleka P Mlisana ${ }^{a b}$, Kamaldeen Babad ${ }^{d}$ and Manormoney Pillay \\ ${ }^{a}$ Department of Medical Microbiology, National Health Laboratory Service, Durban, South Africa \\ ${ }^{\circ}$ Medical Microbiology and Infection Control, School of Laboratory Medicine \& Medical Science, College of Health Sciences, University of KwaZulu- \\ Natal, Durban, South Africa \\ 'Infection Control Services Laboratory, Department of Clinical Microbiology and Infectious Diseases, Witwatersrand Medical School, Johannesburg, \\ South Africa \\ ${ }^{d}$ Department of Medical Microbiology, National Health Laboratory Service, Universitas Academic Laboratory, University of the Free State, \\ Bloemfontein, South Africa \\ *Corresponding author, emails:dr.khine85@gmail.com; Sweswe-han@ukzn.ac.za

Introduction: Carbapenemase production is an important mechanism of carbapenem resistance in Acinetobacter species. This study investigated the presence of the carbapenem-hydrolysing class D $\beta$-lactamase- encoding genes, bla $a_{\mathrm{OXA}-23}$ and $b / a_{\mathrm{OXA}-58}$ and their association with the spread of multidrug-resistant (MDR) Acinetobacter species in intensive care units at an academic hospital.

Method: Forty-four MDR Acinetobacter species were confirmed using VITEK 2 and Epsilometer tests. The $b / a_{\mathrm{OXA}-23}$ and $b / a_{\mathrm{OXA}-58}$ genes were detected by polymerase chain reaction (PCR) in twenty-four selected isolates. The $b / a_{\mathrm{OXA}-23}$ amplicons were sequenced and compared to the GenBank database. Genotypic relatedness of isolates was determined by pulsed field gel electrophoresis (PFGE). Clinical and laboratory data were analysed.

Results: Among the twenty-four isolates, eighteen were carbapenem resistant and six were sensitive. The bla $a_{\text {oxA-23 }}$ gene, but not $b / a_{\mathrm{OXA}-58^{\prime}}$ was detected in the eighteen resistant strains. The $b a_{\mathrm{OXA}-23}$ amplicons showed $100 \%$ identity with the GenBank database of $b a_{\text {OXA-23 }}$. The MICs of carbapenems against Acinetobacter species carrying the $b / a_{\text {OXA-23 }}$ gene were 8 to $>16 \mu \mathrm{g} / \mathrm{ml}$. Genetic relatedness was evident among isolates of seven pairs from fourteen patients. Of these patients, twelve were in the same ICUs and two were adjacent to another ICU during the same hospitalisation period.

Conclusion: The selected MDR Acinetobacter species carried the bla $a_{\mathrm{OXA}-23}$ gene responsible for resistance to carbapenems, while molecular and clinical data analysis suggested horizontal transmission in ICUs. In addition, the PFGE typing of a diverse collection of MDR Acinetobacter species clones showed that isolates were related to no more than two patients, suggesting that no outbreak had occurred.

Keywords: bla $a_{\mathrm{OXA}-23}$ genes, carbapenem-hydrolysing class D $\beta$-lactamases (CHDLs), horizontal transmission, molecular surveillance

\section{Background}

Multidrug-resistant (MDR) Acinetobacter species (Acinetobacter spp.), are both community acquired and nosocomial opportunistic infections and have been responsible for outbreaks around the globe, especially in intensive care units (ICUs). ${ }^{1-5}$ The past twenty years has seen an increase in the prevalence of the pathogen $^{6-8}$ with MDR outbreaks reported in the United States..$^{9-11}$ A significant reservoir is the large number of chronically ill patients ${ }^{5}$ from whom colonisation of recently hospitalised patients may take place. ${ }^{6,7}$

There has been an increase of Acinetobacter spp. resistance to cephalosporins and carbapenems over the years, ${ }^{12-14}$ leaving clinicians with limited therapeutic options. ${ }^{12-14}$ Resistance to carbapenems, which display high efficacy and low toxicity, is of global concern. ${ }^{12-14}$ Surveillance reports from China determined that carbapenem resistance in Acinetobacter spp. doubled from $30 \%$ in 2006 to $63 \%$ in $2013 .{ }^{12-14}$ South African studies revealed Acinetobacter spp. resistance towards carbapenems and cephalosporins, ${ }^{15,16}$ specifically imipenem (86\%), meropenem (86\%) cefepime (90\%) and ceftazidime $(89 \%) .{ }^{16}$
The major mechanism of resistance to $\beta$-lactams in Acinetobacter spp. is carbapenem-hydrolysing class D $\beta$-lactamases (CHDLs), also known as OXA-type enzymes or oxacillinases. ${ }^{16}$ Previous studies classified the class $D$ carbapenemases into four subgroups: associated with OXA-23, OXA-58 as plasmid-encoded and OXA-24, OXA-40, OXA-51 as chromosomally encoded..$^{17,18}$ There are currently five subclasses of OXA associated with Acinetobacter spp.; the intrinsic chromosomal OXA-51-like, of which there are over 70 variants, and the acquired OXA-23-like, OXA-24 (OXA-40-like), OXA-58like, and OXA-143-like. ${ }^{19}$ In addition, the OXA-235, OXA-236, and OXA-237, the first representatives of a novel subclass of CHDLs, were described in A. baumannii strains in 2013. ${ }^{20}$ Enzymes belonging to the OXA-23, OXA-24/40, OXA-48, OXA51, OXA-58, and OXA-143 subgroups are of major clinical importance due to their wide dissemination in bacterial pathogens. ${ }^{21-23}$ The genes encoding these enzymes are widespread ${ }^{20}$ and have been found on both chromosome and plasmids, allowing for spread across Acinetobacter species. ${ }^{20,24}$ The prevalence of OXA- 23 can be attributed to the acquisition of genetic elements, such as plasmids and transposons, as the OXA-23 gene is located on a plasmid or chromosome. ${ }^{16}$ In a 
2012 study, Liakopoulos et al. reported the prevalence of OXA23 in Greece from 2010 to 2011 to be $95 \%,{ }^{25}$ while Koh et al. reported that $91 \%$ of Acinetobacter spp. isolates from Singapore produced carbapenemase and carried the $b / a_{\text {OXA-23 }}$ gene. ${ }^{26}$ Previous studies conducted at Pretoria Academic Hospital revealed the high prevalence of OXA-51 at (83\%, 99\%) and of OXA-23 at (59\%, 77\%) in 2013 and 2015, respectively. ${ }^{16,}$ ${ }^{18}$ Isolates of carbapenem resistant Acinetobacter spp. are often extensively drug-resistant (XDR), since they are susceptible to one or two agents only. ${ }^{27}$ Additionally, the recent rise not only in XDR but also pandrug-resistant (PDR) Acinetobacter spp. ${ }^{22}$ is of global concern. Due to the problem of resistance and antimicrobial availability, the Infectious Diseases Society of America determined that Acinetobacter spp. is a particularly concerning pathogen. ${ }^{28}$ Moreover, the Centers for Diseases Control and Prevention has highlighted the importance of MDR Acinetobacter spp. transmission in nosocomial and community acquired infections. ${ }^{5}$ In our setting, the latter half of 2008 discovered the emergence of Acinetobacter spp. clinical strains with resistance to multiple classes of antimicrobials, including carbapenems, piperacillintazobactam, ceftazidime and fluoroquinolones. Hence, treatment options were restricted to salvage agents like colistin and amikacin.

In this study, we investigated a representative sample of Acinetobacter spp. from Inkosi Albert Luthuli Hospital (IALCH) from 2013 to 2014. We determined the presence of two carbapenem resistance genes using $P C R$, sequencing and correlated the MIC of the carbapenems with the genes. We also investigated the clinical data of patients, including ward of admission, site of specimen, prescribed antibiotics and outcome. Nosocomial spread of the strains was investigated through pulsed field gel electrophoresis (PFGE).

\section{Methods}

\section{Study setting}

The study was conducted at the Department of Medical Microbiology, University of KwaZulu-Natal (UKZN)/National Health Laboratory Service (NHLS). Ethics approval was obtained from the Biomedical Research Ethics Committee, UKZN (Reference No BE 283/12).

The stored Acinetobacter spp. $(n=60)$ isolates had previously been isolated from the patients hospitalised at IALCH from January 2013 to January 2014. Of the sixty, forty-four MDR Acinetobacter spp. were confirmed by using VITEK 2 (BioMérieux, France). The MICs of imipenem and meropenem were determined using the VITEK 2 and Epsilometer tests (E-test) (BioMérieux, France).

Using the antibiogram, four XDR and fourteen MDR isolates with the same sensitivity patterns were selected for molecular investigation. PCR, sequencing and PFGE typing were used to investigate carbapenem-hydrolysing class $D \beta$-lactamase production, the presence of the $b / a_{\mathrm{OXA}-23}$ and bla $a_{\mathrm{OXA}-58}$ genes, as well as the association between drug resistance and presence of the genes.

The A. baumannii ATCC 19606 strain was used as quality control for antimicrobial susceptibility tests and molecular methods. The $b / a_{\mathrm{OXA}-23}$ and bla $a_{\mathrm{OXA}-58}$ carried Acinetobacter spp. isolates obtained from the National Institute for Communicable Diseases (NICD) served as controls for PCR, sequencing and PFGE.

\section{Drug susceptibility testing and MIC}

The stored isolates were confirmed to be MDR Acinetobacter species. Identification and antibiotic susceptibility testing (AST) of MDR Acinetobacter spp., including MICs, were performed using the VITEK ${ }^{\circledR} 2$ GN Card automatic method (BioMérieux France) and the Epsilometer test (E-test ${ }^{\oplus}$ ) (BioMérieux, France) as per the guidelines from the Clinical and Laboratory Standards Institute (CLSI), 2013. ${ }^{29}$

Carbapenem-resistant Acinetobacter spp. were resistant to both imipenem and meropenem with MICs of $8 \mu \mathrm{g} / \mathrm{ml}$, whereas carbapenem-susceptible Acinetobacter spp. possessed a MIC of $<1 \mu \mathrm{g} / \mathrm{ml}$ and carbapenem-intermediate Acinetobacter spp. a MIC of $1-2(<4) \mu \mathrm{g} / \mathrm{ml}^{29}$

\section{Detection of bla ${ }_{O X A-23}$ and bla $a_{O X A-58}$}

Eighteen MDR Acinetobacter spp. belonging to the same antibiogram groups were selected for amplification by PCR to detect the carbapenem resistance genes $b / a_{\mathrm{OXA}-23}$ and $b / a_{\mathrm{OXA}-58}$. Resistance mediating genes were assessed for the presence of polymorphisms with the Big Dye Terminator v3.1 Cycle Sequencing kit (Life Technologies, ThermoFisher Scientific, South Africa).

\section{DNA extraction of Acinetobacter spp. isolates 30,31}

Genomic DNA, from each of twenty-seven isolates, comprising eighteen clinical MDR strains, three controls and six sensitive clinical isolates, was extracted from an overnight culture using a loopful of colonies suspended in $500 \mu \mathrm{l}$ of $1 \mathrm{x}$ TE buffer, pH 8.5 (Tris EDTA) (Capital Laboratory Supplies, Durban, South Africa). Cell lysis and protein digestion were performed using a combination of $10 \%$ sodium dodecyl sulfate and $10 \mathrm{mg} / \mathrm{ml}$ proteinase K (Capital Laboratory Supplies, Durban, South Africa). Proteins were precipitated with $10 \%$ cetyltrimethyl ammonium bromide (CTAB)/4\% NaCl and polysaccharides were extracted by the addition of 24:1 chloroform-isoamyl alcohol (Capital Laboratory Supplies, Durban, South Africa). The DNA was precipitated with isopropanol, washed with $70 \%$ cold ethanol (Capital Laboratory Supplies, Durban, South Africa) and dissolved in an appropriate volume of 1 xTE buffer, $\mathrm{pH}$. The DNA was electrophoresed in a $1 \%$ agarose gel (Capital Laboratory Supplies, Durban, South Africa) to determine quality and quantity. The extracted genomic DNA was stored at $-20{ }^{\circ} \mathrm{C}$ (Defy Ltd, Multimode, South Africa) until further analysis.

\section{Amplication of the bla ${ }_{\text {OXA-23 }}$ and bla ${ }_{O X A-58}$ genes}

The $b / a_{\text {OXA-23 }}$ and $b l a_{\text {OXA-58 }}$ gene regions were amplified using primers (Roche Diagnostics, Randburg, South Africa) specific to the up and downstream regions of the gene sequences (Table 1). The PCR master mix consisted of $5 \mu$ template DNA, 10x PCR

Table 1: Primer sequences and the corresponding annealing temperatures

\begin{tabular}{|c|c|c|c|}
\hline Primers & $\begin{array}{l}\text { Sequence } \\
\left(5^{\prime} \text { to } 3^{\prime}\right)\end{array}$ & $\begin{array}{c}\text { Annealing } \\
\text { temperature }\left({ }^{\circ} \mathrm{C}\right)\end{array}$ & Reference \\
\hline bla $a_{\mathrm{OXA}-23}$ Forward & $\begin{array}{l}\text { TCTGGTTGTACG- } \\
\text { GTTCAGC }\end{array}$ & 53 & [32] \\
\hline$b / a_{\mathrm{OXA}-23}$ Reverse & $\begin{array}{l}\text { AGTCTTTC- } \\
\text { CAAAAATTTTG }\end{array}$ & 53 & [32] \\
\hline$b / a_{\mathrm{OXA}-58}$ Forward & $\begin{array}{l}\text { ATGAAATTAT- } \\
\text { TAAAAATATTGAGT- } \\
\text { TTAG }\end{array}$ & 55 & [32] \\
\hline bla $a_{\text {OXA-58 }}$ Reverse & $\begin{array}{l}\text { TTATAAATAAT- } \\
\text { GAAAAACACCCAAC }\end{array}$ & 55 & [32] \\
\hline
\end{tabular}


buffer, $0.2 \mu \mathrm{M}$ of each primer, $2.5 \mathrm{mM}$ dNTPs, $1 \mathrm{U}$ Taq DNA Polymerase (Thermofisher Scientific, United States), $1.5 \mu \mathrm{M} \mathrm{MgCl}$ and nuclease free water, with a total volume of $25 \mu \mathrm{l}$. The initial denaturation steps were performed for $5 \mathrm{~min}$ at $95^{\circ} \mathrm{C}$, followed by 40 cycles of $20 \mathrm{~s}$ at $95^{\circ} \mathrm{C}, 1 \mathrm{~min}$ at $55^{\circ} \mathrm{C}$ and $30 \mathrm{~s}$ at $72{ }^{\circ} \mathrm{C}$. This was followed by a final extension step of $5 \mathrm{~min}$ at $72^{\circ} \mathrm{C}$. Both positive and negative controls were used during the PCR amplification process. PCR products were electrophoresed on a $1.5 \%$ agarose gel (Capital Laboratory Supplies, Durban, South Africa) with markers of known molecular weights (ThermoFisher Scientific, Waltham, Massachusetts) and visualised under UV light.

\section{Purification of $P C R$ products}

The PCR product were purified using $2 \mathrm{U}$ Shrimp Alkaline Phosphatase (SAP) (AEC-Amersham, Little Chalfont, United Kingdom) and $10 \mathrm{U}$ Exonuclease (Amersham, Little Chalfont, United Kingdom) as per manufacturer's instructions. After the addition of $2 \mathrm{U}$ of SAP and $10 \mathrm{U}$ of Exonuclease I, the PCR tubes were briefly incubated at $32{ }^{\circ} \mathrm{C}$ for $30 \mathrm{~min}$ and then at $80^{\circ} \mathrm{C}$ for $15 \mathrm{~min}$ in a water bath to deactivate the enzymes.

\section{DNA sequencing of bla ${ }_{\text {OXA-23 }}$ amplicons}

Gene sequencing was performed with the ABI Big Dye Terminator v 3.1 Cycle Sequencing kit (ThermoFisher Scientific, Waltham, Massachusetts). The sequenced products were separated by capillary array electrophoresis using the ABI 3500 Genetic Analyser (ThermoFisher Scientific, Waltham, Massachusetts).

The National Center for Biotechnology Information (NCBI) database was accessed and the sample sequences were aligned and compared to a reference sequence using the Basic Local Alignment Search Tool (BLAST) (https://www.ncbi.nlm.nih.gov/).

\section{Genotypic relatedness of clinically selective Acinetobacter spp. determined by PFGE}

Macro-restriction analysis of multidrug-resistant Acinetobacter spp. obtained from IALCH was performed using an adaptation of the method by Seifert et al., ${ }^{33}$ and Sader et al., ${ }^{34}$ Pure isolates from blood agar plates were grown in brain heart infusion (BHI) broth for $15-18 \mathrm{hr}$ at $37{ }^{\circ} \mathrm{C}$ in a shaking incubator (Vacutec, South Africa) for plug preparation. A volume of broth corresponding to 1 optical density (OD) at $600 \mathrm{~nm}$ was used to make a 1\% PFGE agarose plug for each isolate. DNA was extracted within the agarose blocks by cell lysis over 18 hours. Plug slices for each isolate were digested with $20 \mathrm{U}$ Apal restriction endonuclease (New England Biolabs, USA) for $4 \mathrm{hr}$ at $37^{\circ} \mathrm{C}$. The restricted DNA was electrophoresed on a 1\% Pulsed-Field Electrophoresis Gel (BioRad, United States) in 0.5X Tris-Borate-EDTA buffer (Merck, South Africa) at $6 \mathrm{~V} / \mathrm{cm}$ with a $5-25 \mathrm{sec}$ switch time for 24 hours using the Chef-DR 3 system (BioRad, United States).

Cluster analysis was performed according to criteria outlined in Van Belkum et al..$^{35}$ and a type was defined as PFGE banding patterns differing by 4 or less bands. The results were interpreted according to the Tenover criteria. ${ }^{36}$

\section{Clinical and laboratory data collection}

The clinical characteristics, namely type of specimen, ward of admission, prescribed antibiotics and patient outcome, were documented from the patient records. In addition, the laboratory data were recorded from the laboratory computer system. Both the clinical and laboratory data were verified during wards rounds and both were analysed.

\section{Statistical analysis of clinical characteristics and patient outcomes}

Data was captured and analysed using the Statistical Package for Social Sciences (IBM ${ }^{\circledast}$ SPSS Statistics version 19). Results were presented using descriptive statistics such as frequency and percentage. The association between underlying patient condition and response to antibiotic agents was determined using the Pearson chi-square test or Fisher's exact test. Logistic regression was used to test for factors associated with patient mortality.

\section{Results}

\section{Drug susceptibility tests and MICs}

During the study period, forty-four of the sixty stored Acinetobacter spp. isolates were confirmed MDR by the MICs. The selected isolates were resistant to carbapenems, with MIC values for imipenem and meropenem at 8 to $>16 \mu \mathrm{g} / \mathrm{ml}$ as determined by the Vitek (BioMérieux, France) automatic system and confirmed with E-test (BioMérieux, France). The control isolate (ATCC 19606) showed sensitivity to imipenem and intermediate sensitivity to meropenem, with MICs of 0.25 and $1 \mu \mathrm{g} / \mathrm{ml}$ respectively. The bla $a_{\text {OXA-23 }}$ positive control isolate was resistant to imipenem and meropenem with a MIC of $>16 \mu \mathrm{g} / \mathrm{ml}$ for both. The $b / a_{\mathrm{OXA}-58}$ positive control strain was resistant to imipenem and meropenem with a MIC of 8 and $4 \mu \mathrm{g} / \mathrm{ml}$ respectively (Table 2 ).

\section{Clinical characteristics and patient outcomes}

The clinical characteristics and patient outcomes were analysed in those patients whose isolates showed the presence of the bla $\mathrm{OXA-23}$ gene $(n=18)$. Among the eighteen isolates, four $(22 \%)$ were XDR isolates which possessed the same antibiogram and fourteen (78\%) were resistant to all agents except amikacin and colistin (Table 3).

\section{Amplification result of the bla $a_{O X A-23}$ and bla $a_{O X A-58}$ genes by PCR $(n=24)$}

The $b / a_{\mathrm{OXA}-58}$ gene was not detected in any of the isolates tested. The $b / a_{\mathrm{OXA}-23}$ gene was detected in 18 clinical isolates, but not in 6 carbapenem sensitive Acinetobacter spp. isolates (Figure 1, A-D). The majority (17 out of 18) of Acinetobacter spp. isolates carrying the carbapenemase gene exhibited high MICs $(>16 \mu \mathrm{g} / \mathrm{ml})$ to carbapenems (Table 2).

Table 2: MICs of imipenem and meropenem for Acinetobacter spp. isolates from the Central Hospital in the academic complex and the occurrence of the corresponding carbapenemase gene

\begin{tabular}{|c|c|c|c|c|}
\hline $\begin{array}{l}\text { Number of } \\
\text { isolates }(n=24)\end{array}$ & IMP & MEM & $b / a_{\mathrm{OXA} 23}+$ or - & $b / a_{\mathrm{OXA58}}+$ or - \\
\hline 17 & $>16$ & $>16$ & + & - \\
\hline 1 & 8 & $>16$ & + & - \\
\hline 6 & $<0.25$ & $<0.25$ & - & - \\
\hline${ }^{*} b / a_{\mathrm{OXA23}}$ & $>16$ & $>16$ & + & - \\
\hline$*{ }^{*} b l a_{\text {OXA58 }}$ & 8 & 4 & - & + \\
\hline ATCC 19606 & $<0.25$ & 1 & - & - \\
\hline
\end{tabular}

Key: +: detected; -: not detected; IMP: Imipenem; MEM: Meropenem; *: positive control for bla ${ }_{\mathrm{OXA}-23}$ known Acinetobacter spp.; ${ }^{* *}$ : positive control for bla $a_{\mathrm{OXA}-58}$ known Acinetobacter spp. 
Table 3: Clinical characteristics and outcomes of the patients with Acinetobacter spp. isolates with bla $a_{\text {OXA-23 }}$ gene

\begin{tabular}{|c|c|c|}
\hline & \multicolumn{2}{|c|}{ Clinical outcomes $(n=18)$} \\
\hline & $\begin{array}{c}\text { Deceased, } \boldsymbol{n}(\%) \\
7(39 \%)\end{array}$ & $\begin{array}{c}\text { Discharge } n(\%) \\
11(61 \%)\end{array}$ \\
\hline Antibiotics & Resistance $n(\%)$ & Resistance $n(\%)$ \\
\hline Ceftazidime & $7(100 \%)$ & $11(100 \%)$ \\
\hline Ciprofloxacin & $7(100 \%)$ & $11(100 \%)$ \\
\hline Piperacillin-tazobactam & $7(100 \%)$ & $11100 \%)$ \\
\hline Imipenem & $7(100 \%)$ & $11(100 \%)$ \\
\hline Meropenem & $7(100 \%)$ & $11(100 \%)$ \\
\hline Amikacin & $3(17 \%)$ & $1(6 \%)$ \\
\hline \multirow[t]{2}{*}{ Colistin } & 0 & 0 \\
\hline & \multicolumn{2}{|c|}{$p>0.05(0.288)$} \\
\hline ICUs & $5(28 \%) !$ & $9(50 \%) !$ \\
\hline \multirow[t]{3}{*}{ Non-ICUs } & $2(11 \%)$ & $2(11 \%)$ \\
\hline & $p<0.05(0.001) !$ & \\
\hline & \multicolumn{2}{|c|}{$p>0.05(0.515)$} \\
\hline Sterile specimens & $5(28 \%)$ & $6(33 \%)$ \\
\hline \multirow[t]{2}{*}{ Non-sterile specimens } & $2(11 \%)$ & $5(28 \%)$ \\
\hline & \multicolumn{2}{|c|}{$p>0.05(0.417)$} \\
\hline Monotherapy & $3(17 \%)$ & $5(28 \%)$ \\
\hline \multirow[t]{2}{*}{ Combination therapy } & $4(22 \%)$ & $6(33 \%)$ \\
\hline & \multicolumn{2}{|c|}{$p>0.05(0.648)$} \\
\hline \multicolumn{3}{|l|}{$\begin{array}{l}\text { *Horizontal transfer }(n= \\
14 ; 7 \text { pairs) }\end{array}$} \\
\hline${ }^{* *}$ Both in one pair & $4(22 \%)$ & $6(33 \%)$ \\
\hline \multirow{2}{*}{$\begin{array}{l}{ }^{* *} \text { One patient in one } \\
\text { pair }\end{array}$} & $2(11 \%)$ & $2(11 \%)$ \\
\hline & \multicolumn{2}{|c|}{$p>0.05(0.643)$} \\
\hline
\end{tabular}

Key: *: PFGE typing showed horizontal transfer that strains were related from no more than two patients and thus no outbreak occurred during the study period.

**: Among the 7 pairs of patients, 2 pairs in deceased and 3 pairs in discharged.

***: one patient in each pair, in deceased and in discharged.

! $p<0.05$ : the outcomes in ICU was statistically significance $28 \%$ in ICU deceased whereas $50 \%$ survived.

Sterile specimen (BC, blood culture; CSF, cerebrospinal fluid); Non-sterile specimen (ETA, endotracheal aspirate; pus; $C T$, catheter tip); ICUs (N-ICU, Neonatal intensive care unit; ICUT, intensive care unit trauma); Non-ICUs (LW, Labour ward; Neurosurgical ward; High Care unit, Surgical unit, Vascular unit).

\section{Sequencing finding of bla $a_{O X A-23}$ amplicon}

Sequencing of the blaOXA-23-like amplicon of 18 Acinetobacter spp isolates revealed $100 \%$ identity with that from the GenBank database

\section{Correlation between $P C R$ results and MICs of MDR \\ Acinetobacter spp. $(n=18)$}

Table 2 shows the MICs of the eighteen MDR Acinetobacter spp. isolates, correlated with the presence of the CHDL genes. The bla $a_{\mathrm{OXA}-23}$ gene was detected in all the isolates which were phenotypically resistant to carbapenems, with MICs of 8 to $>16 \mu \mathrm{g} /$ $\mathrm{ml}$ for imipenem and meropenem. This gene was not detected in the four carbapenem sensitive strains tested (Figure 1A).
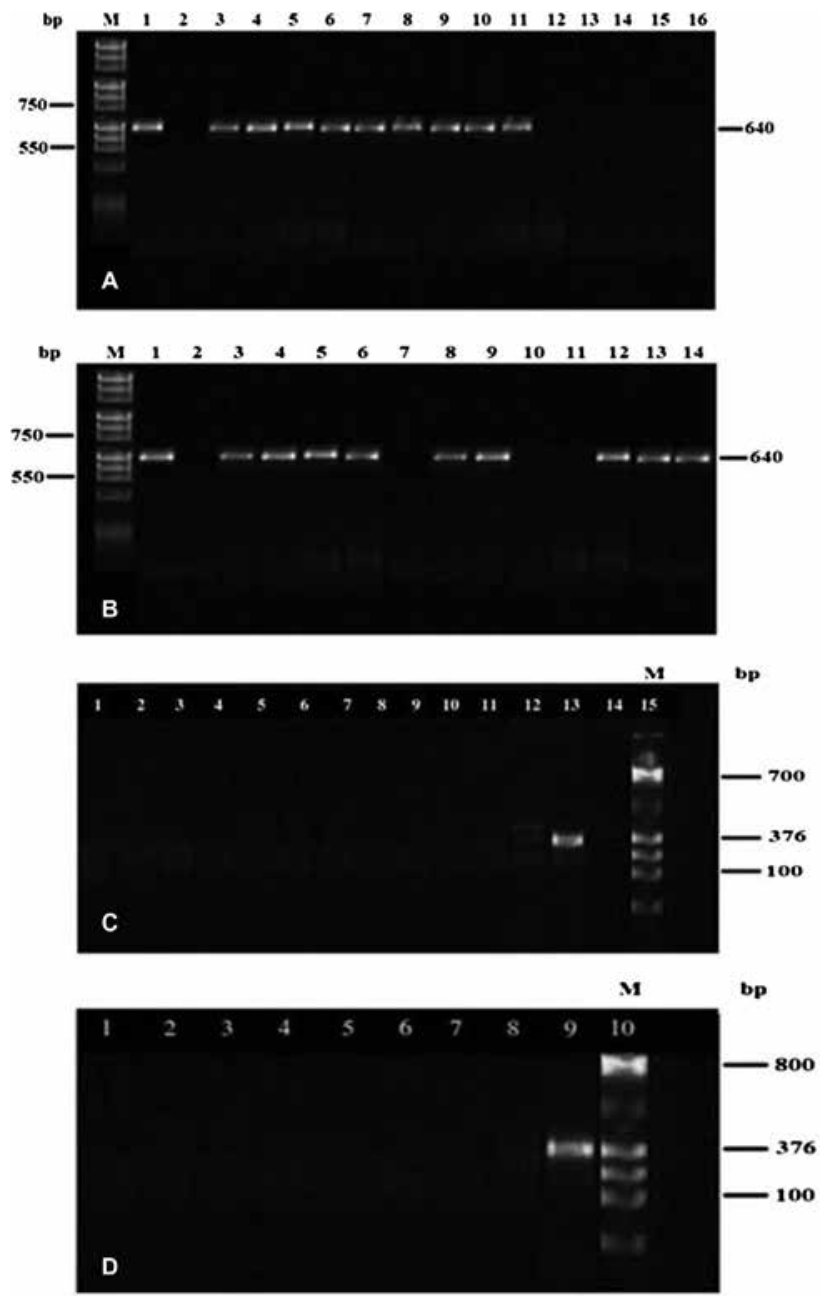

Figure $1 \mathrm{~A}, \mathrm{~B}, \mathrm{C}$ and D: Detection of the Oxacillinase genes (bla $a_{\mathrm{OXA}-23}$ and bla $a_{\text {OXA-58 }}$ genes) in Acinetobacter spp. in a 1.5\% agarose gel following amplification by PCR. Phenotypic resistant Acinetobacter spp. (MDR Acinetobacter spp., 18 isolates). Key: Figure 1A: bla $a_{\text {OXA-23 }}$ amplication product of $640 \mathrm{bp} \mathrm{M}$, molecular weight marker (mW); lane 1, positive control (PC); lane 2, negative control (NC); lanes 3-11, phenotypic resistant Acinetobacter spp. (9 isolates); lanes 12-15, (four isolates were phenotypic sensitive Acinetobacter spp.) lane 16, ATCC 19606 isolate was included. Figure 1B: bla ${ }_{\mathrm{OXA}-23}$ amplication product of 640 bp. M, molecular weight marker (mw); lane 1, positive control (PC); Lane 2, negative control (NC); Lanes 3-6, 8, 9 and 12-14, phenotypic resistant Acinetobacter spp. (9 isolates); Lanes, 10, 11 (two isolates phenotypic sensitive Acinetobacter spp.); Lane 7, ATCC19606 isolate was included. Figure $1 \mathrm{C}$ bla $a_{\mathrm{OXA}-58}$ amplication product of $376 \mathrm{bp} 1 \mathrm{C}$ : Lanes 1- 7, phenotypic MDR Acinetobacter spp., lane 8, ATCC19606, Lane 9, positive control; lane 10, molecular weight markers. Figure ID: bla $a_{\mathrm{OXA}-58}$ amplication product of $376 \mathrm{bp}$. Lanes 1-11, phenotypic MDR Acinetobacter spp. (bla $a_{\text {OXA-58 }}$ gene was not detected) lanes 13, positive controls; lane 14, negative control; Lane 15, molecular weight marker (376 bp); ATCC 19606 isolate was included.

\section{Genotypic relationship between clinically selective} Acinetobacter spp. determined by PFGE $(n=20)$

Twenty Acinetobacter spp. isolates (including controls) were selected according to clinical characteristics for genotyping using PFGE (Figure 2). ${ }^{37}$ The control isolates (ATCC 19606) in lane 26, lane 27 (OXA-23) and lane 28 (OXA-58) showed a fingerprinting pattern different to the rest of the isolates, indicating that the technique was suitably discriminatory for the investigation of their spread (Table 4). 


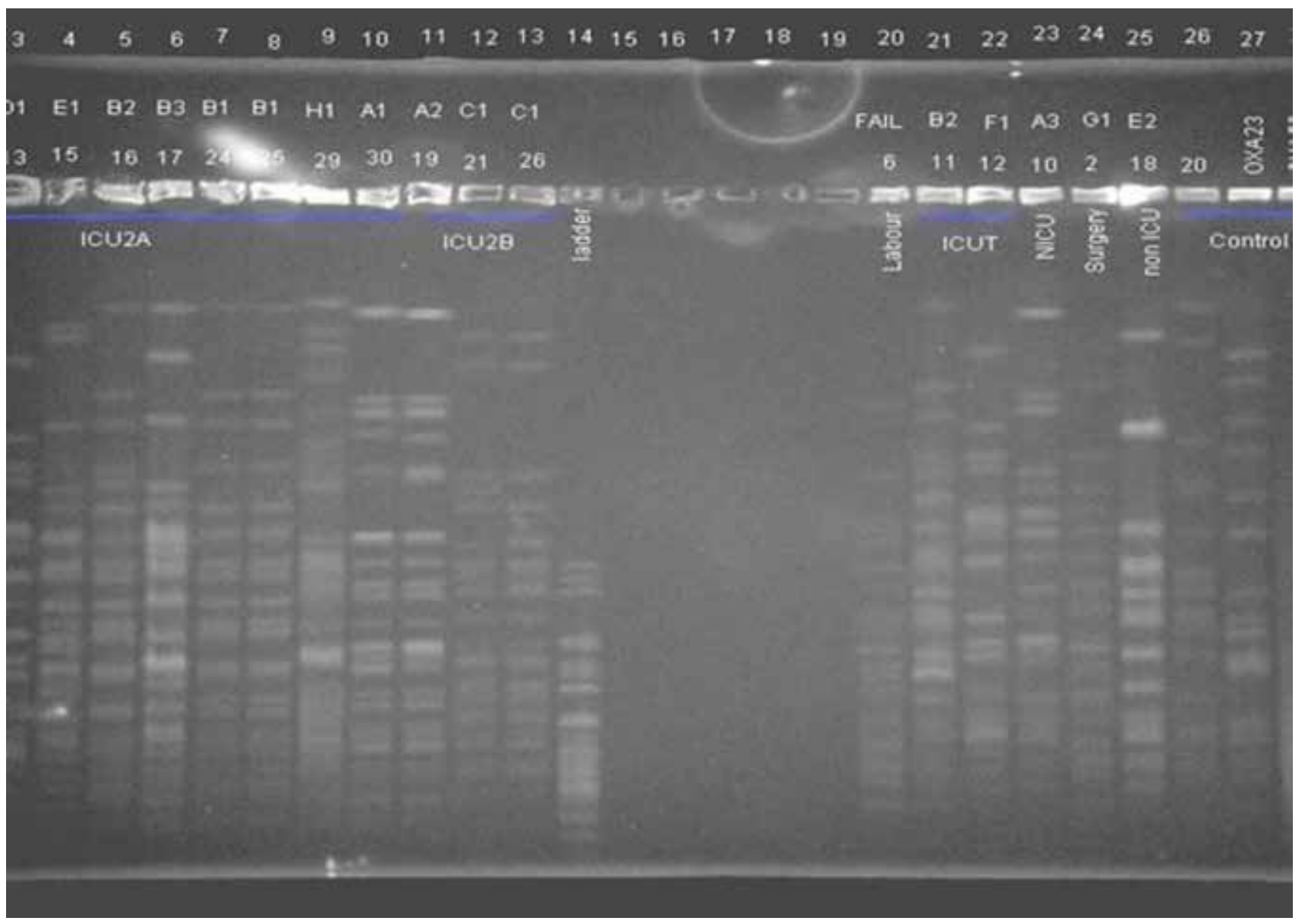

Figure 2: Pulsed field gel electrophoresis results of the OXA-23 producing Acinetobacter spp. Key: Lane 26: ATCC 19606; Lane 27: OXA-23, lane 28: OXA58 strains controls lanes 2, 14, 29, ladders (Salmonella braenderup H9812 used for the DNA ladder); lanes 3-13, isolates 13, 15, 16, 17, 24, 25, 29, 30, 19, 21,26 ; lanes 20 , isolate 6 (failed); lanes $21-25$, isolates $11,12,10,2,18$.

Table 4: PFGE typing interpretation $(n=20)$

\begin{tabular}{|c|c|c|c|c|c|}
\hline No. of pairs (patients) & $\begin{array}{l}\text { Typical no. of } \\
\text { fragment difference } \\
\text { (pulsotypes) }\end{array}$ & Admission date & Specimens & Wards & $\begin{array}{l}\text { Epidemiologic } \\
\text { interpretation / } \\
\text { Comments* }\end{array}$ \\
\hline 1 & 0 & Within a week & BC-CSF & ICU2A-ICU2 B & $\begin{array}{l}\text { Indistinguishable horizon- } \\
\text { tal transfer }\end{array}$ \\
\hline 1 & 0 & Same date & CSF-ETA & ICU2A & $\begin{array}{l}\text { Indistinguishable horizon- } \\
\text { tal transfer }\end{array}$ \\
\hline 1 & 1 & Within a week & $B C-B C$ & ICU2B- NICU & $\begin{array}{l}\text { Closely related horizontal } \\
\text { transfer }\end{array}$ \\
\hline 2 & 2 & Same date & BC- CVPtip CSF-Pus & ICU2A $\times 2^{* *}$ & $\begin{array}{l}\text { Closely related horizontal } \\
\text { transfer }\end{array}$ \\
\hline 1 & 2 & Same date & ETA-Pus & ICUT & $\begin{array}{l}\text { Closely related horizontal } \\
\text { transfer }\end{array}$ \\
\hline 1 & 3 & Within a week & ETA-ETA & VU & $\begin{array}{l}\text { Closely related horizontal } \\
\text { transfer }\end{array}$ \\
\hline 4 & 5 & Within a week & $\begin{array}{l}\text { CVPtip-CSFCVPtip-BCCVP- } \\
\text { tip-PusCVPtip-ETA }\end{array}$ & ICU $2 A \times 4^{* *}$ & Possible related \\
\hline 4 & 6 & Within a week & BC-PusBC-ETA & $\begin{array}{l}\text { ICU2A-ICUTICU2A-VU x } \\
2^{* *} \mid \mathrm{CU} 2 \mathrm{~B}-\mathrm{NICU}\end{array}$ & Possible related \\
\hline 7 & $\geq 7$ & >one week & $\begin{array}{l}\text { ETA-ETAETA-CSFETA- } \\
\text { PusCSF-Pus }\end{array}$ & $\begin{array}{l}\text { ICU2A- NICUICU2A-VU x } \\
4^{* *} \mathrm{VU}-\mathrm{VU}, \mathrm{VU}-\mathrm{ICUT}\end{array}$ & Unrelated \\
\hline
\end{tabular}

Key: PFGE typing interpretation according to Tenover criteria. ${ }^{36}$

*One pair (2 patients) (horizontal transfer between 2 patients/one pair).

**Pairs; 2 pairs of patients in ICU2A and horizontal transfer in each pair, possible related in each pair $x 4$ pairs in ICU2A, possible related in each pair $x 2$ pairs in ICU2A and VU, unrelated in each pair $x 4$ pairs; VU, vascular unit; BC, Blood culture.

CSF, cerebrospinal fluid, ETA, endotracheal aspirate; CVP tip, central venous pressure line tip. 
Two clusters consisting of two isolates each (30 and 19 in lanes 10 and 11) and (24 and 25 in lanes 7 and 8 ) were indistinguishable and identified as horizontal transfer between each pair (Table 4; Figure 2). According to the Tenover criteria, ${ }^{36}$ isolates that demonstrate no band differences are regarded as indistinguishable, and 2-3 band differences are closely related, and are therefore most likely related to each other and interpreted as horizontally transmitted. Isolates with 4-6 band differences are possibly related. The interpretation of PFGE typing results according to the Tenover criteria are shown in Table 4. Based on this interpretation, MDR Acinetobacter spp. were most likely horizontally transferred among seven pairs of patients: six pairs in ICUs and one pair in the Vascular unit (VU).

\section{Correlation between clinical characteristics and laboratory results $(n=44)$}

Of the forty-four stored MDR Acinetobacter spp. isolates, thirtyeight ( $86 \%$ ) and forty-four (100\%) were sensitive to amikacin and colistin respectively (Table 5). The MICs of both imipenem and meropenem against OXA-23 carrying Acinetobacter spp. were high ( 8 to $>16 \mu \mathrm{g} / \mathrm{ml}$ ) (Table 2). The clinical characteristics and outcomes of patients with Acinetobacter spp. producing $b / a_{\mathrm{OXA}-23}$ gene are shown in Table 3. Fourteen (78\%) of the eighteen strains showed identical antibiograms sensitive to amikacin and colistin. Four (22\%) showed the same phenotypic antibiogram and were only sensitive to colistin, therefore defined as XDR. The fourteen (78\%) colstin and amikacin sensitive isolates were obtained from patients in ICUs and the remaining four (22\%) from non-ICUs.

Eleven (61\%) of the eighteen OXA-23 carrying MDR Acinetobacter spp. cultured were from sterile sites, namely blood cultures and CSF, while seven (39\%) were from non-sterile sites such as ETA, pus, catheterised urine and catheter tip.
Eight $(45 \%)$ patients were treated with monotherapy and ten (55\%) with combination therapy. Eleven patients (61\%) were discharged. The seven (39\%) patients who demised were mostly admitted at ICUs among the patients with OXA-23-carrying Acinetobacter spp. (Table 3). Of the seven pairs of patients from whom the horizontally transferred strains were cultured from ICUs (six pairs) and the vascular unit (one pair), both in two pairs demised and three pairs were discharged. Of the remaining two pairs of patients, one of pair demised and one of other pair was discharged (Table 3).

The results clearly indicate there are several pulsotypes of Acinetobacter spp. within wards studied at IALCH (Table 4). There were four distinct pulsotypes identified suggested that there were horizontal transfer of organisms between the ICUs (NICU, ICU2A and ICU2B), horizontal transfer of the organisms between ICUs (ICUT and ICU2A and within ICU2A itself) and there was horizontal transfer of organisms between the ICU2A and the non-ICU (Vascular unit) ward. There were several isolates which were unrelated to the four main pulsotypes. No ascertain could be made regarding how they were acquired in the patients. However, the PFGE typing showed diversity in these collection of MDR Acinetobacter spp. clones, where isolates were related from not more than two patients.

\section{Discussion}

All tested Acinetobacter spp. $(n=44)$ were MDR, defined in the current study as resistant to three or more classes of drugs or carbapenem, ${ }^{27}$ and inclusive of XDR, defined as MDR Acinetobacter spp. resistant to all agents except colistin. Previous studies confirmed that Acinetobacter spp. are resistant to many antibiotics, ${ }^{2-4,12,13,38}$ and susceptibility tests revealed that the strains displayed the colistin-only-sensitive (COS) profile. Multidrug-resistance of Acinetobacter spp. is a major challenge and treatment options for these infections are limited.

Table 5: MICs of appropriate antibiotics $(n=44)$

\begin{tabular}{|c|c|c|c|c|c|c|c|c|c|}
\hline & \multicolumn{9}{|c|}{ MICs $\mu \mathrm{l} / \mathrm{mL}$} \\
\hline No. of isolates $(n=44)$ & TZP & AK & CAZ & CIP & IMP & MEM & CST & Specimen & Ward \\
\hline 21 & $>128$ & 16 & 64 & $>4$ & $>16$ & $>16$ & $<0.5$ & $\mathrm{BC}$ & ICU 2A,2B \\
\hline $3^{*}$ & $>128$ & $>64$ & 64 & $>4$ & $>16$ & $>16$ & $<0.5$ & ETA & ICU2A \\
\hline 3 & $>128$ & 8 & 64 & $>4$ & $>16$ & $>16$ & $<0.5$ & $\mathrm{BC}$ & ICU2B \\
\hline 2 & $>128$ & 8 & 16 & $>4$ & $>16$ & $>16$ & $<0.5$ & TIP & ICU2B \\
\hline 1 & $>128$ & 4 & 8 & $>4$ & $>16$ & $>16$ & $<0.5$ & $\mathrm{BC}$ & ICU2B \\
\hline 1 & $>128$ & 8 & 8 & 2 & $>16$ & $>16$ & $<0.5$ & ETA & ICU2A \\
\hline 1 & $>128$ & 16 & 64 & $>4$ & 8 & $>16$ & $<0.5$ & ETA & ICU2A \\
\hline 2 & $>128$ & $<2$ & 64 & $>4$ & $>16$ & $>16$ & $<0.5$ & PDF & ICUT \\
\hline 1 & $>128$ & 8 & 8 & $>4$ & $>16$ & $>16$ & $<0.5$ & PUS & ICUT \\
\hline 1 & $>128$ & 16 & 64 & $>4$ & 8 & $>16$ & 1 & URINE & ICUT \\
\hline $1^{*}$ & $>128$ & 64 & 64 & $>4$ & 8 & $>16$ & 1 & PUS & Non-ICU \\
\hline 2 & $>128$ & 8 & 32 & $>4$ & $>16$ & $>16$ & $<0.5$ & CSF & Non-ICU \\
\hline $2^{*}$ & $>128$ & 64 & 64 & $>4$ & $>16$ & $>16$ & $<0.5$ & $B C$ & Non-ICU \\
\hline 1 & $>128$ & 16 & 2 & $>4$ & 8 & $>16$ & $<0.5$ & $\mathrm{PF}$ & Non-ICU \\
\hline 1 & $>128$ & 16 & 8 & $<0.25$ & $>16$ & $>16$ & $<0.5$ & ETA & Non-ICU \\
\hline 1 & $>128$ & 4 & 64 & $>4$ & $>16$ & $>16$ & $<0.5$ & FLUID & Non-ICU \\
\hline
\end{tabular}

Key: TZP, piperacillin-tazobactam; AK, amikacin; CAZ, ceftazidime; CIP, ciprofloxacin.

IMP, imipenem; MEM, meropenem; CST, colistin.

*, XDR-Acinetobacter spp. (resistant to all except colistin).

Non-ICUs (High Care unit, Vascular unit, Labour ward, Neurosurgery unit,

Orthopaedic unit). 
This study has demonstrated that carbapenem drugs are no longer active against selected MDR Acinetobacter spp. at local setting (Inkosi Albert Luthuli Academic Complex hospital). The data revealed isolates with high susceptibility to amikacin (86\%) and colistin (100\%) among the forty-four tested MDR Acinetobacter spp. isolates. Therefore, these agents are the mainstay, last resort antibiotics for MDR Acinetobacter spp. in the local setting. In this current situation, there are no standardised guidelines for the management for MDR- and XDR-Acinetobacter spp. infection.

Acinetobacter spp. isolates with the same sensitivity pattern in the antibiograms were selected for molecular investigation, namely four XDR and fourteen MDR isolates. A group of (bla $a_{\mathrm{OXA}-23}$ encoded) OXA-23-carbapenemase-producing MDR and XDR Acinetobacter species were detected in MDR Acinetobacter spp., but no sensitive isolates were identified at ICUs in an academic complex.

The $b / a_{\text {OXA-23 }}$ gene is believed to be responsible for the mechanism of carbapenem antibiotic resistance in Acinetobacter spp. ${ }^{39}$ The OXA-23 gene of carbapenem resistant Acinetobacter spp. was first reported in 1985 in Scotland ${ }^{40}$ and subsequent outbreaks of OXA-23-producing A. baumannii occurred in various locations around the world..$^{39,40}$

MDR Acinetobacter spp. represents a high-risk global and local infection control challenge. ${ }^{40}$ In one study, the gene encoding OXA-23 was found in plasmids, facilitating its spread among Acinetobacter species. ${ }^{14}$ In this study, the spread of bla ${ }_{\mathrm{OXA-23}}$ carried Acinetobacter species was demonstrated by PFGE typing. These findings suggest horizontal transfer between the pairs of patients in ICUs and the vascular unit (Table 4). Moreover, it should be noted that an isolate in the neurology ward adjacent to the ICU unit showed possible relatedness. Thus, it is possible that the establishment of clones in different wards does not account for clonal transmission in hospitals.

The OXA-23 producing MDR Acinetobacter spp. isolates were cultured from both sterile and non-sterile clinical specimens, hence the recommendation for aseptic handling of specimen collection. In addition, hand washing practices need to be audited due to this investigation confirming the dramatic rise of multiple clones with $b / a_{\mathrm{OXA}-23}$ producing MDR Acinetobacter spp. and to control the spread in the local setting. Awareness of the development and existence of drug resistant organisms plays a crucial role in optimising infection control practices, establishing antimicrobial stewardship programs, and establishing active regional surveillance systems. This study also has shown that a correlation between the MDR phenotype and genes related to carbapenem resistance. MDR Acinetobacter spp. with resistant MICs to either of the carbapenem agents may be associated with isolates producing the plasmidmediated or chromosome-mediated gene encoding bla $a_{\mathrm{OXA}-23}$.

During this study time, the antibiograms of all these isolates were phenotypically identical for more than three strains in ICUs. However, the PFGE typing demonstrated a diversity in the MDR Acinetobacter spp. clones, which suggests that isolates were related from not more than two patients per cluster; and, therefore, no outbreak had occurred based on the PFGE typing interpretation. Therefore, isolates with the same antibiogram never-the-less need to be typed genotypically and, at the very least, their MIC values should be checked.

According to data analysis of clinical characteristics, patient outcomes and laboratory data, the clinical outcomes had no association with the following factors: resistance patterns of
Acinetobacter spp. cultured, ICU versus non-ICU wards, sterile sites versus non-sterile sites, and monotherapy versus combination therapy. There was no statistical significance $(p>0.05)$ in each analysis (Table 3). This may be due to the small sample size, which is the main limitation of our study. Continuous surveillance of antibiotic resistance genes in MDR Acinetobacter spp. is crucial for epidemiological purposes and to prevent further dissemination of these genes. In addition, it is necessary to monitor the clinical prevalence and spread of antibiotic resistance genes associated with Acinetobacter spp. Future research should include the detection of other resistance genes, as well as determining the genetic relatedness of Acinetobacter spp. isolates in other hospitals in KZN.

In conclusion, this study discovered that the main carbapenem resistance mechanism of Acinetobacter spp. was due to OXA-23 carbapenemase activity. Although the isolates were spread in ICUs and other ICU related units, there did not seem to be an outbreak according to the demographic clinical data, MICs and PFGE typing (Table 4). Therefore, it is likely that no outbreak had occurred.

This is the first report on epidemiological and molecular observations of Acinetobacter spp. with the detection of the bla $_{\mathrm{OXA}-23}$ gene in MDR Acinetobacter species. Molecular typing of the selected isolates showed that MDR Acinetobacter species carried the $b a_{\text {OXA-23 }}$ gene responsible for resistance to carbapenems (MICs 8 to $>16 \mu \mathrm{g} / \mathrm{ml}$ ). The outcomes provided support for local infection prevention and control management guidelines as part of the antibiotic stewardship programme. Continued molecular surveillance of local epidemiological information and antibiotic resistance surveillance are crucial for infection prevention and control, and is essential in the standard management at the hospital.

Acknowledgement - We gratefully acknowledge the Medical Education Partnership Initiative (MEPI- 5R24TW008863), University of KwaZulu-Natal.Medical Microbiology Department, National Health Laboratory service (NHLS). Dr Teena Thomas (Microbiologist) and Karren le Roux (Medical Scientist) for PFGE typing. Dr Anthony Smith of Pulse Net Africa for providing the strain of Salmonella braenderup H9812 used for the DNA ladder.

\section{Conflict of Interest - None declared.}

Funding - The studies were funded by MEPI, NHLS and UKZN.

\section{ORCID}

\section{Kamaldeen Baba (D) http://orcid.org/0000-0002-0900-1750}

\section{References}

1. Kempf M, Rolain JM. Emergence of resistance to carbapenems in Acinetobacter baumannii in Europe: clinical impact and therapeutic options. Int J Antimicrobial Agents. 2012 Feb 29;39(2):105-14. https://doi.org/10.1016/j.ijantimicag.2011.10.004

2. Abbo A, Navon-Venezia S, Hammer-Muntz O, et al. Multidrug-resistant Acinetobacter baumannii. Emerg Infect Dis. 2005 Jan;11(1):22-9. https://doi.org/10.3201/eid1101.040001

3. Jain R, Danziger LH. Multidrug-resistant Acinetobacter infections: an emerging challenge to clinicians. Ann Pharmacother. 2004 Sep;38(9):1449-59. https://doi.org/10.1345/aph.1D592

4. Rolain JM, Loucif L, Al-Maslamani M, et al. Emergence of multidrugresistant Acinetobacter baumannii producing OXA-23 carbapenemase in Qatar. New Microbes New Infect. 2016 May;31(11):47-51. https://doi.org/10.1016/j.nmni.2016.02.006 
5. Ziglam H, Elahmer O, Amri S, et al. Antimicrobial resistance patterns among Acinetobacter baumannii isolated from burn intensive care unit in Tripoli, Libya. Int Arab J Antimicr Agents. 2012 Oct 22; 2(3).

6. Weinstein RA, Gaynes R, Edwards JR. National Nosocomial Infections Surveillance System. Overview of nosocomial infections caused by gram-negative bacilli. Clin Infect Dis. 2005 Sep 15;41(6):848-54. https://doi.org/10.1086/432803

7. Gonzalez-Villoria AM, Valverde-Garduno V. Antibiotic-resistant Acinetobacter baumannii increasing success remains a challenge as a nosocomial pathogen. J Pathogens. 2016 Feb;4:2016.

8. Giamarellou H, Antoniadou A, Kanellakopoulou K. Acinetobacter baumannii: a universal threat to public health? Int J Antimicrob Agents. 2008 Aug;32(2):106-19.https://doi.org/10.1016/j.jjantimicag.2008.02.013

9. Karlowsky JA, Draghi DC, Jones ME, et al. Surveillance for antimicrobial susceptibility among clinical isolates of Pseudomonas aeruginosa and Acinetobacter baumannii from hospitalized patients in the United States, 1998 to 2001. Antimicrob Agents Chemother. 2003 May 1;47(5):1681-88. https://doi.org/10.1128/AAC.47.5.1681-1688.2003

10. Landman D, Quale JM, Mayorga D, et al. Citywide clonal outbreak of multiresistant Acinetobacter baumannii and Pseudomonas aeruginosa in Brooklyn, NY: the preantibiotic era has returned. Arch Intern Med. 2002 Jul 8;162(13):1515-20. https://doi.org/10.1001/archinte.162.13.1515

11. Maslow JN, Glaze T, Adams P, et al. Concurrent outbreak of multidrugresistant and susceptible sub clones of Acinetobacter baumannii affecting different wards of a single hospital. Infect Control Hosp Epidemiol. 2005 Jan;26(01):69-75. https://doi.org/10.1086/502489

12. Peleg AY, Seifert H, Paterson DL. Acinetobacter baumannii: emergence of a successful pathogen. Clin Microbiol Rev. 2008 Jul;21(3):538-82. https://doi.org/10.1128/CMR.00058-07

13. Fupin H, Demei Z, Fu W, et al. CHINET 2013 Surveillance of bacterial resistance in China. Chin J Infect Chemother. 2014;(14):365-74.

14. Chang $Y$, Luan $G, X u Y$, et al. Characterisation of carbapenem-resistant Acinetobacter baumannii isolates in a Chinese teaching hospital. Front Microbiol. 2015 Sep;1(6):910.

15. Perovic O, Fortuin-de Smidt M, Chetty V. Antimicrobial resistance surveillance from sentinel public hospitals, South Africa, 2013. Comm Dis Surveil Bull. 2014;12:30-58.

16. Lowings $M$, Ehlers $M M$, Dreyer $A W$, et al. High prevalence of oxacillinases in clinical multidrug-resistant Acinetobacter baumannii isolates from the Tshwane region, South Africa - An update. BMC Infect Dis. 2015 Nov 14;15(1):521. https://doi.org/10.1186/s12879015-1246-8

17. Vahaboglu H, Budak F, Kasap M, et al. High prevalence of OXA-51type class $D \beta$-lactamases among ceftazidime-resistant clinical isolates of Acinetobacter spp.: co-existence with OXA-58 in multiple centres. J Antimicrob Chemoth. 2006 Sep 1;58(3):537-42. https://doi.org/10.1093/jac/dkl273

18. Kock MM, Bellomo AN, Storm N, et al. Prevalence of carbapenem resistance genes in Acinetobacter baumannii isolated from clinical specimens obtained from an academic hospital in South Africa. South Afr J Epidemiol Infect. 2013 Jan 1;28(1):28-32.

19. Poirel L, Naas T, Nordmann P. Diversity, epidemiology, and genetics of class D $\beta$-lactamases. Antimicrob Agents Chemother. 2010 Jan 1;54(1):24-38. https://doi.org/10.1128/AAC.01512-08

20. Higgins PG, Pérez-Llarena FJ, Zander E, et al. OXA-235, a novel class D $\beta$-lactamase involved in resistance to carbapenems in Acinetobacter baumannii. Antimicrob Agents Chemother. 2013 May 1;57(5):2121-26. https://doi.org/10.1128/AAC.02413-12

21. Kishii K, Kikuchi K, Tomida J, et al. The first cases of human bacteremia caused by Acinetobacter seifertii in Japan. J Infect Chemotherapy. 2016 May 31;22(5):342-45. https://doi.org/10.1016/j.jiac.2015.12.002

22. Yang $Y$, Wang J, Fu Y, et al. Acinetobacter seifertii isolated from China: genomic sequence and molecular epidemiology analyses. Medicine. 2016 Mar; 95(9).

23. Durante-Mangoni E, Zarrilli R. Global spread of drug-resistant Acinetobacter baumannii: molecular epidemiology and management of antimicrobial resistance. Future Microbiol. 2011 Apr;6(4):407-22. https://doi.org/10.2217/fmb.11.23
24. Antunes NT, Lamoureaux TL, Toth $M$, et al. Class D $\beta$-lactamases: are they all carbapenemases? Antimicrob Agents Chemother. 2014 Apr 1;58(4):2119-25. https://doi.org/10.1128/AAC.02522-13

25. Liakopoulos A, Miriagou V, Katsifas EA, et al. Identification of OXA23-producing Acinetobacter baumannii in Greece, 2010 to 2011. Euro Surveil. 2012;17:1-3.

26. Koh TH, Sng LH, Wang GC, et al. IMP-4 and OXA $\beta$-lactamases in Acinetobacter baumannii from Singapore. J Antimicrob Chemother. 2007 Apr 1;59(4):627-32. https://doi.org/10.1093/jac/dkl544

27. Magiorakos AP, Srinivasan A, Carey RB, et al. Multidrug-resistant, extensively drug resistant and pan drug-resistant bacteria: An international expert proposal for interim standard definitions for acquired resistance. Clin Microbiol Infect. 2012 Mar 1;18(3):268-81. https://doi.org/10.1111/j.1469-0691.2011.03570.x

28. Talbot GH, Bradley J, Edwards JE Jr, et al. Bad bugs need drugs: an update on the development pipeline from the antimicrobial availability task force of the infectious Diseases Society of America. Clin Infect Dis. 2006 Mar 1;42(5):657-68. https://doi.org/10.1086/499819

29. Clinical Laboratory Standards Institute. M1-S23, Performance standards for antimicrobial susceptibility testing, Twenty-Third Informational Supplement. Wayne: CLSI; 2013.

30. Boom R, Sol CJ, Salimans MM, et al. Rapid and simple method for purification of nucleic acids. J Clin Microbiol. 1990 Mar 1;28(3):495-503.

31. Koeleman JG, Stoof J, Van Der Bijl MW, et al. Identification of epidemic strains of Acinetobacter baumannii by integrase gene PCR. J Clin Microbiol. 2001 Jan 1;39(1):8-13. https://doi.org/10.1128/JCM.39.1.8-13.2001

32. Hujer KM, Hujer AM, Hulten EA, et al. Analysis of antibiotic resistance genes in multidrug-resistant Acinetobacter spp. isolates from military and civilian patients treated at the Walter Reed Army Medical Center. Antimicrob Agents Chemother. 2006 Dec 1;50(12):4114-23. https://doi.org/10.1128/AAC.00778-06

33. Seifert $H$, Schulze A, Baginski R, et al. Comparison of four different methods for epidemiological typing of Acinetobacter baumannii. J Clin Microbiol. 1994 Jul 1;32(7):1816-19.

34. Sader HS, Mendes SF, Pignatari C, et al. Use of macro restriction analysis to demonstrate inter hospital spread of multiresistant Acinetobacter baumannii in Sao Paulo. Brazil. Clin Infect Dis. 1996 Sep 1;23(3):631-4. https://doi.org/10.1093/clinids/23.3.631

35. Van-Belkum A, Tassios PT, Dijkshoorn L, et al. Guidelines for the validation and application of typing methods for use in bacterial epidemiology. Clin Microbiol Infect Dis. 2007 Oct 1;13(3):1-46. https://doi.org/10.1111/j.1469-0691.2007.01786.x

36. Tenover FC, Arbeit RD, Goering RV, et al. Interpreting chromosomal DNA restriction patterns produced by pulsed-field gel electrophoresis: criteria for bacterial strain typing. J Clin Microbiol 1995;33(9):2233.

37. Goering RV. Pulsed field gel electrophoresis: a review of application and interpretation in the molecular epidemiology of infectious disease. Infect Genet Evol. 2010 Oct 31;10(7):866-75. https://doi.org/10.1016/j.meegid.2010.07.023

38. Manikal VM, Landman D, Saurina G, et al. Endemic carbapenemresistant Acinetobacter species in Brooklyn, New York: citywide prevalence, interinstitutional spread, and relation to antibiotic usage. Clin Infect Dis. 2000 Jul 1;31(1):101-6. https://doi.org/10.1086/313902

39. Chagas TP, Carvalho KR, de Oliveira Santos IC, et al. Characterisation of carbapenem-resistant Acinetobacter baumannii in Brazil (20082011): countrywide spread of OXA-23-producing clones (CC15 and CC79). Diagnostic Microbiol Infect Dis. 2014 Aug 31;79(4):468-72. https://doi.org/10.1016/j.diagmicrobio.2014.03.006

40. Perez F, Hujer AM, Hujer KM, et al. Global challenge of multidrugresistant Acinetobacter baumannii. Antimicrob Agents Chemother. 2007 Oct 1;51(10):3471-84. https://doi.org/10.1128/AAC.01464-06

Received: 28-11-2016 Accepted: 24-05-2017 